\title{
John Law and Evelyn Ruppert (eds) (2016) Modes of Knowing: Resources from the Baroque. Manchester: Mattering Press. 265 pages. ISBN: 978-0-9931449-8-1
}

\author{
Sarah Pilar lacobucci
}

sarahiac@ucm.es

Theatricality. Boundlessness. Heterogeneity. Folding: both one and two. Distribution, movement and self-consciousness. Mediation. These are the techniques of baroque art that one of the editors of Modes of Knowing: Resources from the Baroque, John Law, lists in the introduction as amongst those which make the qualities of otherness, emotion, and embodiment (p. 29) so crucial to baroque modes of knowing and doing. The book sets off from the widely discussed point that the ways in which we know the world are not given, but are part of distinct political, social, and historical constellations, and ways of doing the world. Focusing on our conventional ways of knowing as social scientists, Law compiles a list of those things which we often "bracket, forget, and conceal" ( $p$. 19) in our interpretation and representations: passion, bodies, material heterogeneity, excess, specificity, formlessness, performativity (p. 19-20). STS and other fields have identified and attempted to tackle these lacks in various ways, but in this book we are presented with the baroque as a possible way of knowing and doing that provides an exciting way to engage with these qualities that have been othered from academia for so long. As Law states in the introduction, the baroque "knew extravagantly and excessively" and "knew itself to be performative" (p. 23), among other characteristics. Thus, given that many of the qualities of this way of knowing have been long espoused as alternatives throughout STS and other fields, the baroque is presented as "a storehouse of possible alternative techniques" (p. 23).

For a reader who might be numbed by many of the academic constraints they find themselves shackled within when doing their work, the way in which the baroque seems to provide a way out of so many of these constraints is incredibly interesting. The book is an edited volume of contributions made by participants of the workshop 'The Baroque as Empirical Sensibility'. It divides itself into two halves. The first half groups those essays which reflect upon qualities of the baroque by using them to interpret their research, while the second half is intended to encompass those chapters that experiment with performing a baroque way of knowing.

Blaser's chapter in Part I, along with other parts of the book, deals with parts of the baroque's notorious history of being a technique of dominating religious or colonised subjects, addressing doubts that could make many a reader wary of adopting this perspective and way of doing. "A baroque sensibility is neither dominatory nor transgressive. Which of these forms it takes depends on specifically situated relations" (p. 60). Using community participatory workshops in the Yshiro Indigenous community in Paraguay, Blaser demonstrates how excess is produced and used in, on the one hand, the development community, where it comes about from their horror ignotum (horror of the unknown) of indigenous visions and 
ways of life, and on the other hand, from the indigenous standpoint, where it comes to be other ways of knowing and doing. By making evident the destructive qualities of desperate attempts to know, to fight horror ignotum, Blaser proposes a very interesting question for those considering a baroque mode of knowing in general: "might it actually just end up adding more techniques to escape the ghost of horror ignotum?" (p. 81). Much of the book is occupied with a baroque mode of knowing's transgressive qualities, but a possible critique that could be made of it is not reflecting enough on how it could slip into a dominating role, as hinted at in Blaser's question.

To be fair, however, this is addressed in a way in another one of the book's outstanding contributions by Mattijs van de Port. Van de Port grapples with the question of how to bring the feeling of being lost in what he calls "the rest-of-what-is", or Lacan's real, the whole of the hole, without domesticating or making these experiences graspable. Speaking about how the Church, in baroque art, tried to "colonise' the experiences of the ineffable" (p. 181), he calls upon us to be careful to not do the same by replacing this colonising role with that of the authority of academy, which might try to explain away these experiences. Thus, I see here another way in which the book cautions the reader into what could be slippages away from the baroque's possible transgressiveness.

One of the most important themes I found in the book, which were included in van de Port's chapter, Evelyn Ruppert's wonderful chapter, and several others, was that of how the baroque can be a way of doing that plays with the performativity of one's works. As Law notes in the introduction, "we rarely set out to write texts intended to induce ecstasy-or loss of self in any form-in the reader... the knowing subject is much more selfcontained" (p. 26). In explaining her proposed sensory sociology, which shares much in common with a baroque perspective, Ruppert speaks about how this type of sociology recognizes the performative and inventive qualities of social research, that they are "not innocent but political" (p. 146). This political aspect is very important to keep in mind when we think about what we want our social research in general to do. By showing how the $(\mathrm{x})$ trees project by the Mexican artist
Agnes Chavez enacts data visualization in a very different way to most social researchers, so as to provoke an "immersive and embodied" experience (p. 154) where "excess is not contained but flows" (p. 156) Ruppert shows how this brings about an "active, contemplative, and engaged subject" (p. 157). Using baroque qualities to bring about this type of subject or experience is also seen in van de Port's chapter as he concludes with the idea that visual art could be used in conjunction with our research to help them experience the ineffable, and identify more with whatever subjects our research may be about and "a greater commitment to find ways to relieve their plight" (p. 192). Given that one could presume that most researchers in STS wish to make some difference in the world with their research, these discussions seem very important. Another chapter that highlights this performativity is that of Helen Verran and Brit Ross Winthereik in which they question what different diagrams can do.

Another interesting theme which was touched upon throughout the book were the artifacts and aesthetics that form part of the institutions of knowing in academia that keep the othered qualities of the baroque out. These ranged from the effects and things different diagrams might do, to the feelings of constraint produced when trying to explain unspeakable emotions in a "vacuum-cleaned conference room, full of spotless white Fornica tables" (van de Port p. 168), to formal academic writing conventions. As Law makes clear in the introduction, these constraints are embedded in certain institutional histories and material conditions, but it might have been interesting if the book had included a chapter or some thoughts on how academic institutions or gatherings could change to foster more baroque ways of knowing and doing: the material conditions that could foster these reflections more.

Annemarie Mol's chapter, the last in the book, which aims to explore baroque coherence, is another one of the highlights of the collection. It finishes off the book quite nicely, because within all the characteristic baroque chaos: no inside, no outside, who is what, no center, etc, in which we might get lost and think anything goes, she uses the clafoutis to show that, while this is a particularly good symbol of the precariousness of the 
baroque as a composition, it "does not mean that anything goes" (p. 258). But what exactly makes a clafoutis a clafoutis is performed constantly and elastic, and not possible to pin down, needing to be just so, an idea which escapes our intellectual grasp. A fantastic chapter to tie together the baroque: it does have a coherence, but these are temporary and performative.

In all, I would highly recommend this book to anyone in social research interested in reflecting upon how they do their work, and what their work does in the world. 